\title{
Relation between bradycardia dependent long QT syndrome and QT prolongation by disopyramide in humans
}

Hiroshi Furushima, Shinichi Niwano, Masaomi Chinushi, Kouji Ohhira, Akira Abe, Yoshifusa Aizawa

\begin{abstract}
Background-Recent molecular biological investigations have identified abnormal genes in familial forms of long QT syndrome, but in bradycardia dependent acquired long QT syndrome, no such genetic abnormality has yet been identified.

Objective-To investigate the relation between the responses of QT interval to pacing change and to disopyramide.

Methods-This study included 13 patients with bradyarrhythmia who had undergone pacemaker implantation. The patients were divided into two groups: group I $(n=8)$, patients with QT prolongation (QT interval $\geqslant 500 \mathrm{~ms}$ ) during bradycardia; group II $(n=5)$, patients without QT prolongation (QT interval $<500 \mathrm{~ms}$ ) during bradycardia. The responses of QT interval caused by the change of pacing rate were determined and compared with the changes of the QT interval after disopyramide administration.

Results-The QT interval in group I was significantly longer than that in group II when the pacing rate was decreased from 110 to 50 beats/min: mean (SD) 451 (16) $v$ $416(17) \mathrm{ms}$ at 90 beats $/ \mathrm{min}(p=0.0033)$, and $490(19) v 432$ (18) $\mathrm{ms}$ at 70 beats/min $(p=0.0002)$, respectively. The QT interval was prolonged significantly by disopyramide in both groups, but the change was more pronounced in group $I$ than in group II: 78 (33) $v 35$ (10) $\mathrm{ms}(\mathrm{p}<0.05)$.

Conclusions-This study suggests that the patients showing bradycardia dependent
\end{abstract} 31 July 1997

Table 1 Relation between $Q T$ interval and heart rate

\begin{tabular}{lllll}
\hline & \multicolumn{4}{l}{$Q T$ interval (ms) at each heart rate (beats/min) } \\
\cline { 2 - 5 } Patient number & 110 & 90 & 70 & 50 \\
\hline Group I & & & & \\
1 & 420 & 460 & 500 & 520 \\
2 & 400 & 440 & 480 & - \\
3 & 420 & 460 & 500 & - \\
4 & 400 & 440 & 480 & - \\
5 & 420 & 460 & 500 & 520 \\
6 & 390 & 420 & 460 & 480 \\
7 & 440 & 460 & 480 & 500 \\
8 & 440 & 470 & 520 & 550 \\
Mean (SD) & $416(18)$ & $451(16)$ & $490(19)$ & \\
Group II & & & & \\
9 & 400 & 420 & 440 & 460 \\
10 & 380 & 400 & 420 & - \\
11 & 420 & 440 & 460 & 480 \\
12 & 400 & 420 & 420 & - \\
13 & 380 & 400 & 420 & - \\
Mean (SD) & $396(17)$ & $416(17)$ & $432(18)$ & \\
\hline
\end{tabular}

QT prolongation are also more markedly affected by disopyramide and that abnormal potassium channel may be the underlying mechanism.

(Heart 1998;79:56-58)

Keywords: bradycardia; long QT syndrome; disopyramide

In congenital long QT syndrome, recent molecular biological evidence has demonstrated abnormal genes related to potassium channel or sodium channel. ${ }^{1-3}$ Torsades de pointes $(\mathrm{TdP})$ is an important complication of bradyarrhythmias, ${ }^{4-6}$ when it is associated with the QT prolongation but the mechanism of bradycardia induced QT prolongation is poorly understood. Whether bradycardia induced QT prolongation is caused by the abnormal potassium current remains to be determined. $^{7-9}$ In this study, the effect of disopyramide on the QT interval was studied in patients with bradycardia induced QT prolongation and compared with that in patients without this prolongation.

\section{Methods}

PATIENTS

The study included 13 patients (seven men and six women) with bradyarrhythmia (mean (SD) age 68 (14) years, range, 31 to 83 ). All had undergone pacemaker implantation. The diagnosis was sick sinus syndrome $(n=7)$ and complete atrioventricular block $(n=6)$. The patients were divided into two groups: eight patients (five men and three women) with QT interval $\geqslant 500 \mathrm{~ms}$ (group I) and five patients (two men and three women) with QT interval $<500 \mathrm{~ms}$ (group II) during bradycardia (38 (8), range 21 to 47 beats/min, no significant difference between groups). The two groups did not have a significant difference for any clinical background feature.

STUDY PROTOCOL: QT INTERVAL RESPONSE TO PACING

Electrocardiograms were obtained on a six channel FX-4100 (Fukuda Denshi Inc, Japan) at a paper speed of $50 \mathrm{~mm} / \mathrm{s}$ with a calibration of $10 \mathrm{~mm} / \mathrm{mV}$, and the QT interval was measured from the onset of the QRS in the sinus rhythm or from the pacing spike during pacing to the end of the T wave usually in lead II or V3-5. QTc was calculated according to Bazett's formula $\left(\mathrm{QT}_{\mathrm{c}}=\mathrm{QT} / \sqrt{\mathrm{RR}}\right)$. 


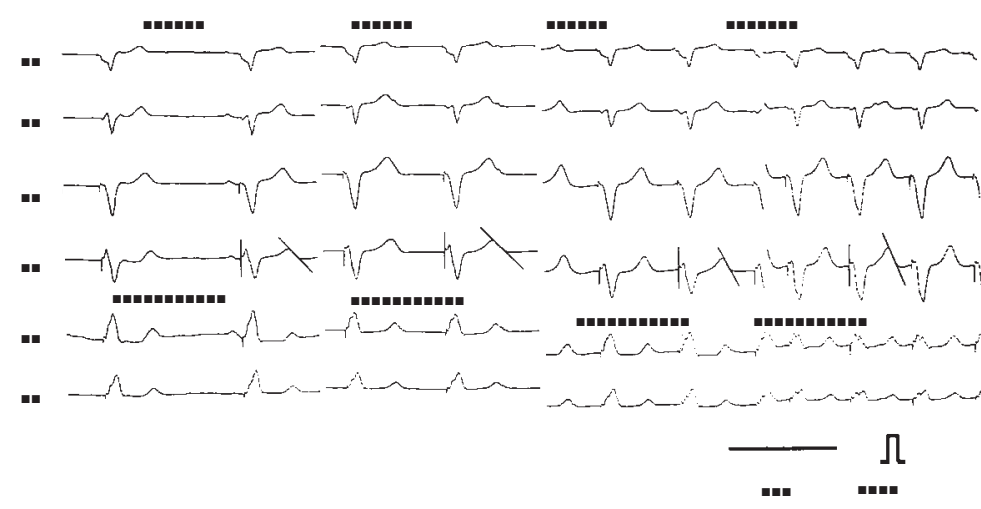

Figure 1 The QT interval responses to different pacing rates in a patient in group I. The pacing rate was decreased from 110 to 50 beats/min and the QT interval was measured, which was prolonged from 440 to $550 \mathrm{~ms}$.

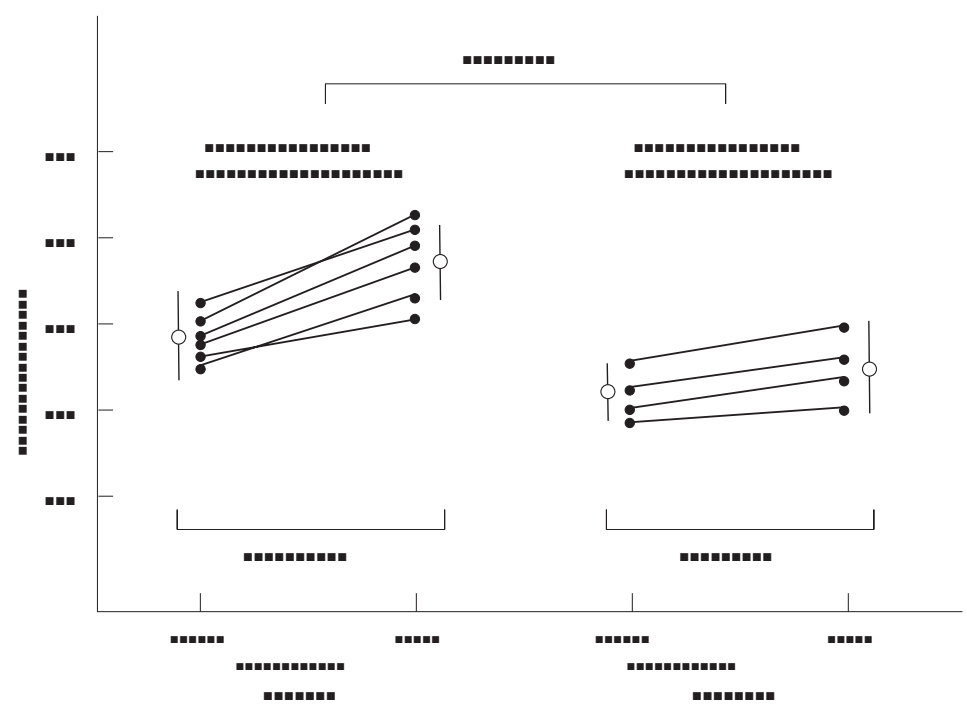

Figure 2 QT prolongation induced by disopyramide in each group. The $Q T$ interval was prolonged after disopyramide administration in both groups. The change of the QT interval induced by disopyramide was more pronounced in group $I$.

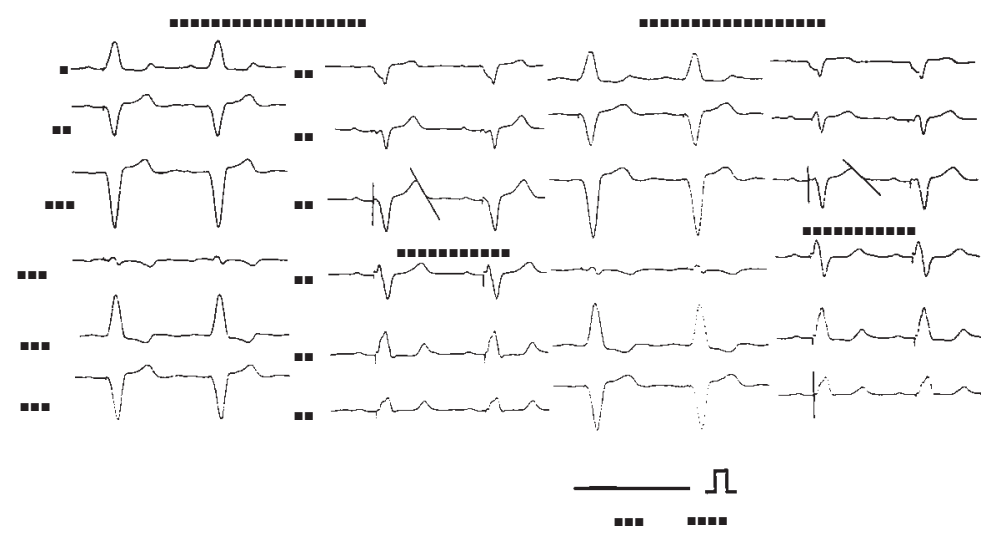

Figure 3 Change of the QT interval induced by disopyramide in patients with $Q T$ interval prolongation during bradycardia (group I). The net change of the $Q T$ interval is $90 \mathrm{~ms}$.

We examined the QT interval at various heart rates and compared the intervals in group I with those in group II. Ventricular pacing at 110 beats $/ \mathrm{min}$ was reduced in decrements of 20 beats $/ \mathrm{min}$ to 50 beats $/ \mathrm{min}$. Pacing at each rate was continued for at least five minutes, and the QT interval was confirmed to be stabilised.
QT INTERVAL RESPONSE TO DISOPYRAMIDE

In five patients in group I and four patients in group II, disopyramide (50 mg) was given intravenously while the heart was paced at constant rate, and the QT interval was measured before and after the disopyramide administration. The responses in the two groups were compared. Blood pressure was measured during this part of the study.

\section{STATISTICAL ANALYSIS}

All data are expressed as mean (SD). The paired or unpaired Student's $t$ test was used to compare the continuous data. A p value $<0.05$ was considered significant.

\section{Results}

PATIENT CHARACTERISTICS

No patient had organic heart disease except for one patient in group I who had cardiac sarcoidosis. The cardiac thoracic ratios were not significantly different in the two groups. No familial involvement of the QT interval could be demonstrated in either group.

QT INTERVAL RESPONSE TO VENTRICULAR RATE

Table 1 lists the responses of the QT interval to pacing rate. The QT intervals in group I were not significantly prolonged compared with those in group II at a pacing rate of 110 beat/min. However, the QT interval in group I was significantly prolonged compared with that in group II when the pacing rate was decreased to $70-90$ beats $/ \mathrm{min}$, being 451 (16) v $416(17) \mathrm{ms}$, respectively, at 90 beats $/ \mathrm{min}$ $(\mathrm{p}=0.0033)$, and $490(19) v 432(18) \mathrm{ms}$, respectively, at 70 beats $/ \mathrm{min}(\mathrm{p}=0.0002)$. The QT interval was longer at low rates in group I than group II. Figure 1 shows a typical example of the QT interval changes in relation to heart rate in group $\mathrm{I}$.

QT INTERVAL RESPONSE TO DISOPYRAMIDE ADMINISTRATION

Figure 2 shows the responses of the QT interval to disopyramide. Before disopyramide administration the QT interval in group I (478 (29) ms) was slightly more prolonged than that in the group II (415 (34) ms) at the pacing rate of $63(5)$ and $62(6)$ beats $/ \mathrm{min}$, respectively $(\mathrm{p}<0.05)$. The QT interval was prolonged by disopyramide administration, from $478(29) \mathrm{ms}$ to $533(47) \mathrm{ms}(\mathrm{p}<0.05)$ in group I, and from 415 (34) $\mathrm{ms}$ to 450 (42) ms $(p<0.05)$ in group II, and the change of the QT interval caused by disopyramide was significantly $(\mathrm{p}<0.05)$ more pronounced in group I (78 (33) ms v $35(10) \mathrm{ms}$, respectively). Figure 3 shows a representative example of the change in QT interval in a patient in group I.

RELATION BETWEEN THE PACING INDUCED VERSUS DISOPYRAMIDE INDUCED PROLONGATION OF THE QT INTERVAL

The changes of the QT interval provoked by the two interventions were fairly well correlated: $r=0.69,(\mathrm{p}<0.05)$. 


\section{Discussion}

Recently, genetic mutations have been identified in familial forms of long QT syndrome, and the existence was confirmed of at least three abnormal genes that encode either potassium channel ${ }^{610}$ or sodium channel. ${ }^{11}$ The defects are considered to delay the repolarisation and result in prolonged duration of the action potential and the QT interval. The mechanism of long QT syndrome, however, is still poorly understood. Recently we demonstrated that acetylcholine induced prolongation of the QT interval only in patients with long QT syndrome. ${ }^{12}$

Bradycardia is known to precipitate long QT syndrome and $\mathrm{TdP},{ }^{13-16}$ and we sometimes observe a pronounced QT prolongation in some patients, but the mechanism of such bradycardia induced QT prolongation is not known.

Class Ia antiarrhythmic agents like quinidine, disopyramide, and procainamide have all been reported to induce long QT syndrome and TdP..$^{7-9}{ }^{17} 18$ For quinidine and disopyramide, Jane et al reported a biphasic response in action potential duration: at low concentration, the QT interval is prolonged, particularly at slow rates (reverse rate dependence), ${ }^{19-20}$ but it is shortened at higher drug concentration. ${ }^{15}$ The QT prolongation is considered to result from the blocking effect of the potassium channel. ${ }^{21-23}$

In this study, the patients who had QT prolongation during bradycardia showed more prominent QT prolongation as heart rate decreased, as expected from the clinical findings. Furthermore, the QT interval was more markedly prolonged by disopyramide in these patients, and the changes caused to heart rate and those to disopyramide were well correlated $(r=0.69)$. The mechanisms of these pronounced prolongations of QT interval at low rate and after disopyramide administration are unknown. Recently, Tao et $a l^{24}$ suggested that $\mathrm{IKr}$ plays an important part in producing a reverse use dependence of action potential duration, but if bradycardia induced long QT syndrome is associated with abnormal IKr and if disopyramide induced QT prolongation shares the same potassium channel or not remain to be studied.

Our study shows that patients with QT interval prolongation during bradycardia display a pronounced rate dependency of the QT interval, and it seems possible to identify such patients using the class Ia agent disopyramide. Potential risk of developing $\mathrm{TdP}$ at slow rate might be screened by using disopyramide.

Two important limitations of this study were that the patient groups were not homogenous and the number of patients was small. However, most patients with sick sinus syndrome or atrioventricular block show normal QT interval, even at an extremely slow rate but the patients with QT interval prolongation during bradycardia seem to represent a distinct subgroup with latent long QT syndrome. Data should be accumulated for a larger number of patients.

1 Keating M, Atkinson D, Dunn C, Timothy K, Vincent GM, Leppert M. Linkage of a cardiac arrhythmia, the long QT syndrome, and Harvey ras-1 gene. Science 1991;252:704-6. 2 Curran ME, Splawski I, Timothy KW, Vincent Gmm, Curran ME, Splawski I, Timothy KW, Vincent Gmm, Green ED, Keating MT. A molecular basis for cardiac
arrhythmia: HERG mutations cause long QT syndrome. arrhythmia: HERG mutl $1995 ; 81: 795-803$.

3 Sanguinetti MC, Jiang C, Curran ME, Keating MT. Amechanistic link between an inherited and an acquired cardiac arrhythmia: HERG encodes the Ikr potassium channel. Cell 1995;81:299-307.

4 Keren E, Tzivoni D, Gavish D. Etiology, warning signs and therapy of torsade de pointes: a study of 10 patients. Circulation 1981;64:263-72.

5 Smith WM, Gallagher JJ. "Les torsades de pointes": an unusual ventricular arrhythmia. Ann Intern Med 1980;93: $578-84$

6 Strasberg B, Kusniec J, Erdman S, Lewin RF, Arditti A, Sclarovski S. Polymorphous ventricular tachycardia and atrioventricular block. Pacing Clin Electrophysiol 1986;9: 522-6.

7 Jackman WM, Friday KJ, Anderson JL, Aliot EM, Clark M, Lazzara R. The long OT syndrome: a critical review, new Lazzara R. The long QT syndrome: a critical review, new
clinical observations and a unifying hypothesis. Prog Cardiovasc Dis 1988;31:115-72.

8 Roden DM. The long QT syndrome and torsade de pointes: basic and clinical aspects. In: El-Sherif N, Samet P, eds. Cardiac pacing and electrophysiology. 3rd ed. Philadelphia: WB Saunders, 1991:265-84

9 El-Sherif N, Bekheit S, Henkin R. Quinidine-induced long QTU interval and torsade de pointes: role of bradycardiadependent early afterdepolarization. $f \mathrm{Am}$ Coll Cardiol 1989;14:252-7.

10 Vincent BM. Hypothesis for the molecular physiology of the Romano-Ward long QT syndrome. $7 \mathrm{Am}$ Coll Cardiol 1992;20:500-3.

11 Wang Q, Shen J, Splawski I, Atkinson D, Li Z, Robinson JL, et al. SCN5A mutations associated with an inherited cardiac arrhythmia, long QT syndrome. Cell 1995;80:80511 .

12 Aizawa Y, Washizuka T, Igarashi Y, Kitazawa H, Chinushi $\mathrm{M}$, Abe A, et al. Acetylcholine-induced prolongation of the QT interval in idiopathic long QT syndrome. Am f Cardiol QT interval in idiopa

13 Brachmann J, Scherlag BJ, Rosenshtraukh LV, Lazzara R. Bradycardia-dependent triggered activity: relevance to drug-induced multiform ventricular tachycardia. Circulation 1983;68:846-56.

14 Roden DM, Hoffman BF. Action potential prolongation and induction of abnormal automaticity by low quinidine concentrations in canine purkinje fibers: relationship to potassium and cycle length. Circ Res 1985;56:857-67.

15 Kurita T, Ohe T, Marui N, Aihara N, Takaki H, Kamakura $\mathrm{S}$, et al. Bradycardia-induced abnormal QT prolongation in patients with complete atrioventricular block with torsade de pointes. Am $\mathcal{F}$ Cardiol 1992;69:628-33.

16 Jurkiewicz NK, Sanguinetti MC. Rate-dependent prolongation of cardiac action potentials by a methanesulfonanilide class III antiarrhythmic agent: specific block of rapidly activating delayed rectifier K current by dofetilide. Circ Res 1993;72:75-83.

17 Roden DM, Woosley RL, Primm RK. Incidence and clinical features of the quinidine-associated long QT syndrome: implications for patient care. Am Heart F 1986:111:108893.

18 Balser JR, Roden DM, Bennett PB. Single inward rectifier potassium channels in guinea pig ventricular myocytes: effects of quinidine. Biophys f 1991;59:150-61.

19 Jane AB, Kenneth R, Wyse JC, Terence JC. Quinidine but not disopyramide prolongs cardiac purkinje fiber action potential after a pause. $\mathcal{F}$ Cardiovasc Pharmacol 1994;23: 833-7.

20 Hondeghem LM, Synders DJ. Class III antiarrhythmic agents have a lot of potential but a long way to go. Reduced effectiveness and dangers of reverse use-dependence. Circulation 1990;81:686-90.

21 Wyse KR, Ye V, Campbell TJ. Action potential prolongation exhibits simple dose-dependence for sotalol, but reverse dose-dependence for quinidine and disopyramide: implicadion for proarrhythmia due to triggered activity. $f$
tion tion for proarrhythmia due to trigge
Cardiovasc Pharmacol 1993;21:316-22.

22 Colatsky TJ. Modulation of cardiac repolarization currents by antiarrhythmic drugs. In: Rosen MR, Janse MJ, Wit AL, eds. Cardiac electrophysiology: a textbook. New York: Futura 1991:1043-62.

23 Carmeliet E, Saikawa T. Shortening of the action potential and reduction of pacemaker activity by lidocaine, quinidine, and procainamide in sheep cardiac Purkinje fibers: an effect on Na or K currents? Circ Res 1982;50:257-72.

24 Tao Y, Roden DM. Extracellular potassium modulation of drug block of Ikr: implication for torsade de pointes and reverse use-dependence. Circulation 1996;93:407-11. 